\title{
The Impact of Atorvastatin on Cardiac Performance for Dilated Cardiomyopathy: A Meta-analysis of Randomized Controlled Studies
}

\author{
Lin Fu, MD*, Xiaoyang Shang, MD*, Xiaoshan Zhang, MD \\ Department of Ultrasonic, The Affiliated Hospital of Neimogo Medical University, Neimogo, China
}

\section{ABSTRACT}

Introduction: The efficacy of atorvastatin for dilated cardiomyopathy remains controversial. We conducted a systematic review and meta-analysis to explore the influence of atorvastatin on cardiac performance for dilated cardiomyopathy.

Methods: We searched PubMed, Embase, Web of Science, EBSCO, and Cochrane library databases through February 2019 for randomized controlled trials (RCTs) assessing the effect of atorvastatin on cardiac performance for dilated cardiomyopathy. This meta-analysis was performed using the random-effects model.

Results: Five RCTs involving 401 patients were included in the meta-analysis. Overall, compared with control groups for dilated cardiomyopathy, atorvastatin treatment resulted in a significantly positive impact on left ventricular ejection fraction (standard mean difference $[\mathrm{SMD}]=0.58 ; 95 \%$ confidence interval $[\mathrm{CI}]=0.33$ to $0.84 ; P<.00001)$, 6 -minute walk test $(\mathrm{SMD}=0.79 ; 95 \% \mathrm{CI}=0.27$ to $1.31 ; P=.003)$, N-terminal pro-brain natriuretic peptide $(\mathrm{SMD}=-0.60 ; 95 \% \mathrm{CI}=-1.18$ to $-0.01 ; P=.04)$, left ventricular systolic volume $(\mathrm{SMD}=0.41$; $95 \% \mathrm{CI}=0.03$ to $0.79 ; P=.03$ ), low-density lipoprotein (SMD $=-1.37 ; 95 \% \mathrm{CI}=-1.92$ to $-0.82 ; P=.00001)$, and C-reactive protein $(\mathrm{SMD}=-0.47 ; 95 \% \mathrm{CI}=-0.72$ to $-0.22 ; P=.0002)$, but showed no obvious influence on left ventricular end-diastolic volume $(\mathrm{SMD}=0.14 ; 95 \% \mathrm{CI}=-0.37$ to $0.64 ; P=.59)$.

Conclusions: Atorvastatin treatment provides significant benefits for dilated cardiomyopathy.

\section{INTRODUCTION}

Dilated cardiomyopathy is diagnosed based on dilation and systolic dysfunction of the left ventricle, and patients with coronary artery disease, hypertension, valvular heart disease, or congenital heart disease are excluded from this diagnosis [Kaski 2007; Weintraub 2017; McNally 2017]. Dilated cardiomyopathy occurs with increased frequency in men

Received October 25, 2019; accepted February 27, 2020.

*These authors contributed equally to this work.

Correspondence: Xiaobin Zhang, MD, No. 1 Tongdaobei Road, Huimin District, Neimogo 010050, China; 860411-84671291; fax: 860411-84671291. (e-mail:13947133133@163.com). between the ages of 20 and 60 years and often results in congestive heart failure with high morbidity and mortality [Kaski 2007; Bielecka-Dabrowa 2011]. Autoimmunologic processes are reported to be an important etiologic factor in the pathogenesis of dilated cardiomyopathy [Maisch 2005].

In addition to lipid-lowering and anti-atherosclerotic effects, statins have important pleiotropic properties such as the inhibition of signal transmission from membrane receptors, pathologic remodeling of the heart and vessels, the action of angiotensin II, and apoptosis [Yoshida 2017; Diamantis 2017; Labos 2018]. Statins are also found to retard the progression of heart failure symptoms and reduce the level of N-terminal pro-brain natriuretic peptide (NTproBNP), indicating the potential protective influence on heart failure and myocardium [Martin 2005]. Atorvastatin therapy is reported to reduce the incidence of sudden cardiac death in patients with advanced heart failure [Vrtovec 2008]. In congestive heart failure, statin therapy results in fewer readmissions for adverse events, blunted inflammatory activation, and improved left ventricular (LV) performance [Correale 2011].

However, current evidence is insufficient for routine clinical use of atorvastatin for dilated cardiomyopathy. Recently, several reports have examined the efficacy of atorvastatin for dilated cardiomyopathy, but the results have been conflicting

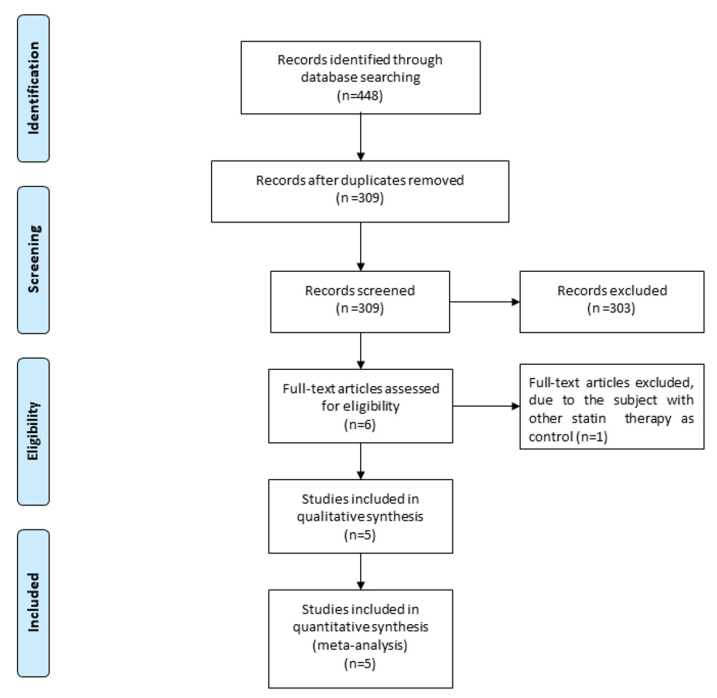

Figure 1. Flow diagram of study search and selection process. 


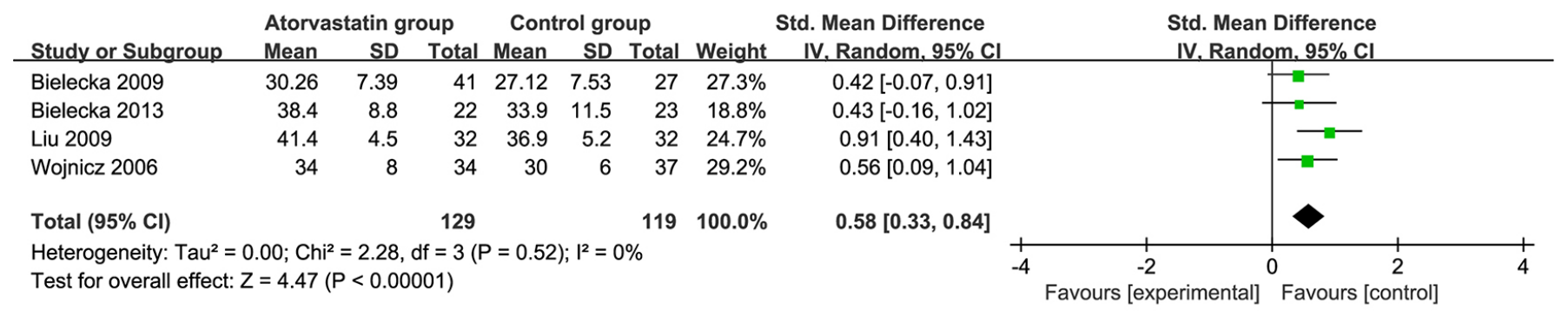

Figure 2. Forest plot for the meta-analysis of LVEF (\%).

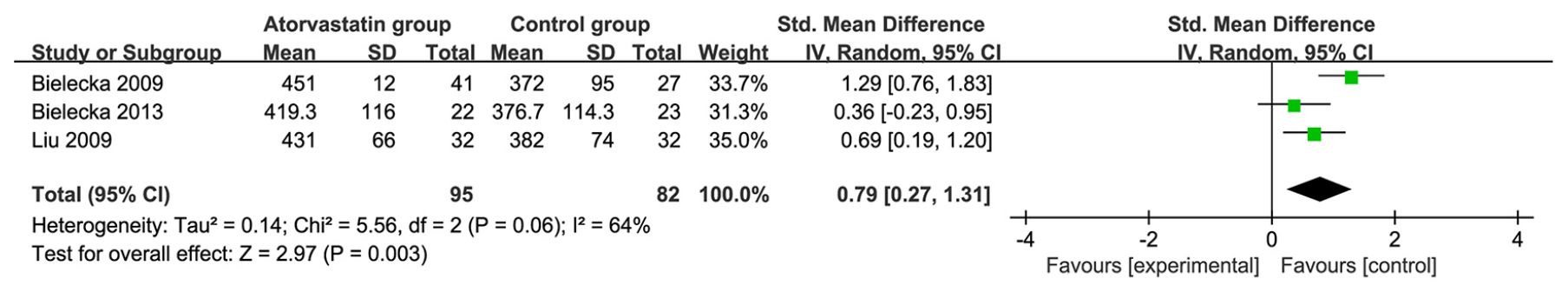

Figure 3. Forest plot for the meta-analysis of 6-MWT (m).

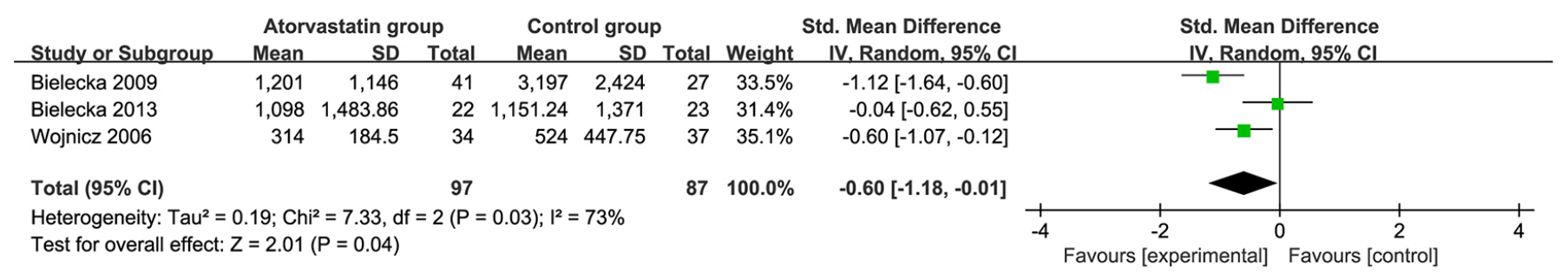

Figure 4. Forest plot for the meta-analysis of NT-proBNP.

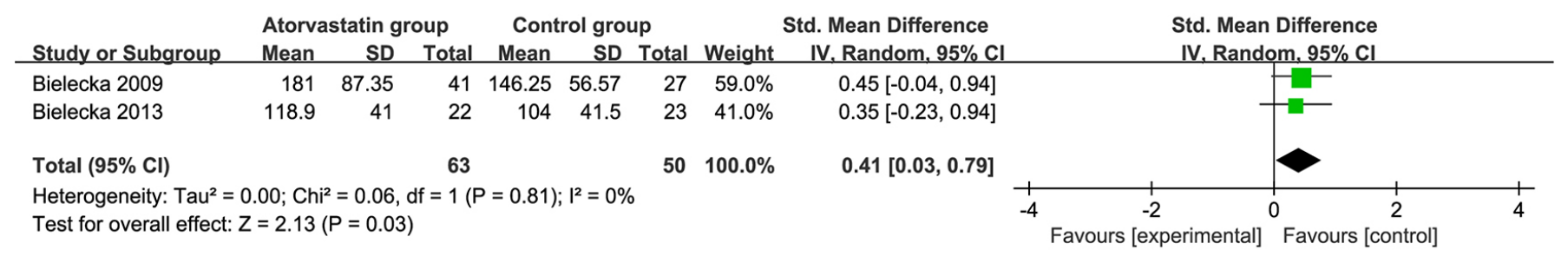

Figure 5. Forest plot for the meta-analysis of LVsV (mL).

[Bielecka-Dabrowa 2013; Liu 2009; Bielecka-Dabrowa 2009]. This systematic review and meta-analysis of randomized controlled trials (RCTs) aims to assess the efficacy of atorvastatin in patients with dilated cardiomyopathy.

\section{METHODS}

This systematic review and meta-analysis was performed based on the guidance of the Preferred Reporting Items for Systematic Reviews and Meta-analysis statement and Cochrane Handbook for Systematic Reviews of Interventions [Moher 2009; Higgins 2011]. No ethics approval or patient consent was required because all analyses are based on previously published studies.

\section{Literature Search and Selection Criteria}

We systematically searched several databases including PubMed, Embase, Web of Science, EBSCO, and the Cochrane library from inception to February 2019 with the 
Characteristics of included studies*

\begin{tabular}{|c|c|c|c|c|c|c|c|c|c|c|c|c|c|}
\hline Study & & & & & NYHA & & & & & & NYHA & & $\begin{array}{l}\text { Jadad } \\
\text { Score }\end{array}$ \\
\hline $\begin{array}{l}\text { Bielecka- } \\
\text { Dabrowa } \\
2013\end{array}$ & 22 & $\begin{array}{c}59.0 \pm \\
11.0\end{array}$ & NR & NR & NR & $\begin{array}{l}40 \mathrm{mg} / \mathrm{d} \text { for } 2 \mathrm{mo} \text {, } \\
\text { then individually } \\
\text { matched dose of } 10 \\
\text { or } 20 \mathrm{mg} / \mathrm{d}\end{array}$ & 23 & $\begin{array}{c}59.0 \pm \\
11.0\end{array}$ & NR & NR & NR & Placebo & 3 \\
\hline Liu 2009 & 32 & $\begin{array}{c}49.4 \pm \\
6.4\end{array}$ & 10 & $\begin{array}{c}20.89 \pm \\
3.27\end{array}$ & $15 / 17$ & 10 mg/d p.o. & 32 & $\begin{array}{c}51.9 \pm \\
5.2\end{array}$ & 12 & $\begin{array}{c}21.22 \pm \\
2.37\end{array}$ & $17 / 15$ & Placebo & 5 \\
\hline $\begin{array}{l}\text { Bielecka- } \\
\text { Dabrowa } \\
2009\end{array}$ & 41 & $56 \pm 10$ & 3 & $\begin{array}{c}29.08 \pm \\
4.94\end{array}$ & $18 / 19$ & $\begin{array}{c}40 \mathrm{mg} / \mathrm{d} \text { for } 2 \mathrm{mo} \text {, } \\
10 \mathrm{mg} \text { for } 4 \mathrm{mo}\end{array}$ & 27 & $59 \pm 14$ & 7 & $\begin{array}{c}24.8 \pm \\
3.5\end{array}$ & $9 / 13$ & $\begin{array}{l}\text { No } \\
\text { statin } \\
\text { therapy }\end{array}$ & 4 \\
\hline $\begin{array}{l}\text { Bleske } \\
2006\end{array}$ & 9 & $56 \pm 11$ & NR & NR & NR & $80 \mathrm{mg}$ for $12 \mathrm{wk}$ & 6 & $56 \pm 11$ & NR & NR & NR & Placebo & 3 \\
\hline
\end{tabular}

*NR indicates not reported.

keywords "atorvastatin" and "dilated cardiomyopathy." The reference lists of retrieved studies and relevant reviews were also hand-searched, and the process above was performed repeatedly to include additional eligible studies.

The inclusion criteria were as follows: (1) RCT study design, (2) patients diagnosed with dilated cardiomyopathy, and (3) intervention treatment of atorvastatin versus placebo or no statin therapy.

\section{Data Extraction and Outcome Measures}

Some baseline information was extracted from the original studies, including first author, number of patients, age, body mass index (BMI), New York Heart Association (NYHA) functional class, and detailed methods in 2 groups. Data were extracted independently by 2 investigators, and discrepancies were resolved by consensus. We contacted the corresponding authors to obtain the data when necessary. The primary outcome was LV ejection fraction (LVEF). Secondary outcomes were 6-minute walk test (6-MWT), NT-proBNP, LV systolic volume (LVsV), LV end-diastolic volume (LVEdV), lowdensity lipoprotein (LDL), and C-reactive protein (CRP).

\section{Quality Assessment in Individual Studies}

The methodological quality of each RCT was assessed with the Jadad scale (1 to 5 points), which consists of 3 evaluation elements: randomization ( 0 to 2 points), blinding ( 0 to 2 points), and dropouts and withdrawals (0 to 1 point) [Jadad 1996]. One point is allocated to each element if they were conducted and mentioned appropriately in the original article. An article with a Jadad score $\leq 2$ is considered to be of low quality, and one is considered to be of high quality with a Jadad score $>3$ [Kjaergard 2001].

\section{Statistical Analysis}

We assessed the standard mean differences (SMDs) with $95 \%$ confidence intervals (CIs) for continuous outcomes (LVEF, 6-MWT, NT-proBNP, LVsV, LVEdV, LDL, and CRP). Heterogeneity was evaluated using the I2 statistic, with I $2>50 \%$ indicating significant heterogeneity [Higgins 2002]. The random-effects model was used for all metaanalysis. We searched for potential sources of heterogeneity for significant heterogeneity. Sensitivity analysis was performed to detect the influence of a single study on the overall estimate by omitting 1 study in turn or performing the subgroup analysis. Owing to the limited number $(<10)$ of included studies, publication bias was not assessed. Results are considered as statistically significant for $P<.05$. All statistical analyses were performed using Review Manager Version 5.3 (The Cochrane Collaboration, Oxford, UK).

\section{RESULTS}

\section{Literature Search, Study Characteristics, and Quality Assessment}

Figure 1 shows the detailed flowchart of the search and selection results. Initially, 448 potentially relevant articles were identified. Finally, 5 RCTs were included in the 


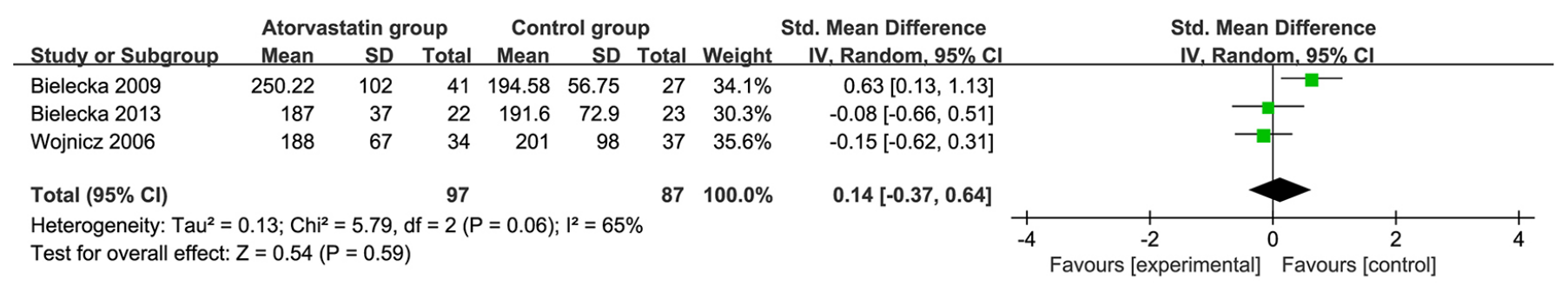

Figure 6. Forest plot for the meta-analysis of LVEdV $(\mathrm{mL})$.

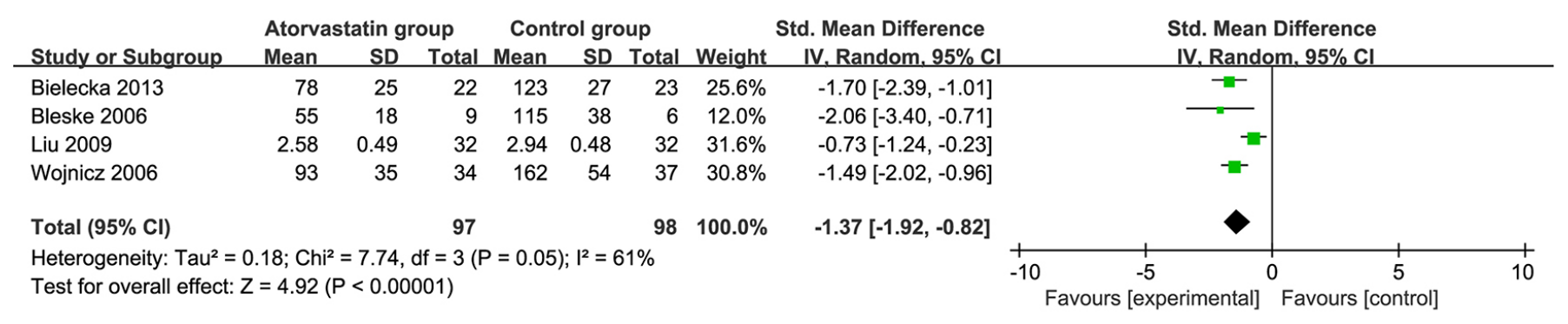

Figure 7. Forest plot for the meta-analysis of LDL cholesterol.

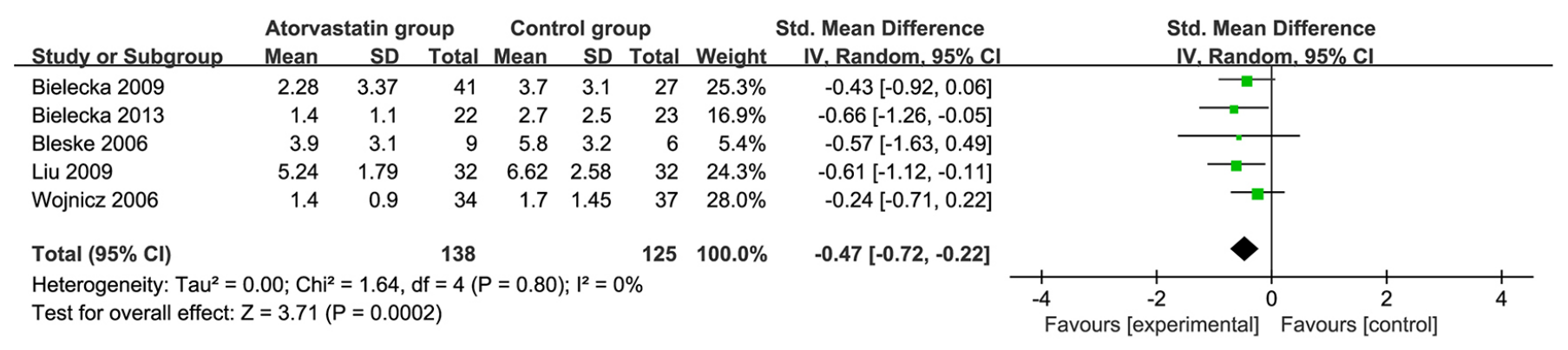

Figure 8. Forest plot for the meta-analysis of CRP (mg/L).

meta-analysis [Bieleck-Dabrowa 2013; Liu 2009; BieleckaDabrowa 2009; Wojnicz 2006; Bleske 2006].

The baseline characteristics of the included RCTs are shown in Table 1. These studies were published between 2006 and 2013, and the total sample size was 401. The doses of atorvastatin ranged from 10 to $80 \mathrm{mg}$ daily. Jadad scores of the 5 included studies varied from 3 to 5 , and all 5 studies were of high quality based on the quality assessment.

\section{Primary Outcome: LVEF}

The random-effects model was used for the analysis of LVEF. Compared with a control group for dilated cardiomyopathy, atorvastatin can substantially increase LVEF (SMD $=0.58 ; 95 \% \mathrm{CI}=0.33$ to $0.84 ; P<.00001)$, with no heterogeneity among the studies $\left(I^{2}=0 \%\right.$ heterogeneity, $\left.P=.52\right)$ (Figure 2).

\section{Sensitivity Analysis}

There was no heterogeneity for the primary outcome, and thus we did not perform sensitivity analysis.

\section{Secondary Outcomes}

In comparison with control interventions for dilated cardiomyopathy, atorvastatin was associated with significantly increased 6-MWT (SMD $=0.79 ; 95 \% \mathrm{CI}=0.27$ to $1.31 ; P=$ .003) (Figure 3), reduced NT-proBNP (SMD $=-0.60 ; 95 \%$ $\mathrm{CI}=-1.18$ to $-0.01 ; P=$.) (Figure 4$)$, and improved LVsV $(\mathrm{SMD}=0.41 ; 95 \% \mathrm{CI}=0.03$ to $0.79 ; P=.03)($ Figure 5$)$. There was no statistical difference in LVEdV between the 2 groups $(\mathrm{SMD}=0.14 ; 95 \% \mathrm{CI}=-0.37$ to $0.64 ; P=.59)$ (Figure 6). $\mathrm{LDL}(\mathrm{SMD}=-1.37 ; 95 \% \mathrm{CI}=-1.92$ to $-0.82 ; P=.00001)$ (Figure 7 ) and CRP (SMD $=-0.47 ; 95 \% \mathrm{CI}=-0.72$ to -0.22 ; $P=.0002$ ) (Figure 8) in the atorvastatin group were remarkably lower than in the control group.

\section{DISCUSSION}

Statins can reduce the synthesis of cholesterol by inhibiting the enzyme 3-hydroxy-3-methylglutaryl coenzyme A reductase [Nunes 2017; Oesterle 2017; Naito 2017]. This 
mechanism also accounts for derivatives of mevalonic acid (eg, isoprenoids) [Wassmann 2001]. Statins have negative impact on the function of cytoplasmic regulatory proteins-GTPases from the Rho protein family (e.g., Ras, Rac1, and Rap) by limiting the production of isoprenoids, and this results in increased angiogenesis and myocardial perfusion, decreased myocardial apoptosis, and improvement in endothelial and cardiac function [Yoon 2009].

Statins are also found to inhibit the synthesis of inflammatory cytokines and chemokines, improve autonomic function, and reverse myocardial remodeling [Banach 2009; Banach 2005]. After 12 weeks of therapy with fluvastatin $80 \mathrm{mg} /$ day, considerable improvement of ventricular function and clinical symptoms of cardiac insufficiency are observed in dilated cardiomyopathy patients, and the concentration of IL-6 is also decreased [Gurgun 2008]. Atorvastatin $40 \mathrm{mg}$ daily for 2 months is applied for dilated cardiomyopathy patients, and the 5-year results reveal its benefits in NT-proBNP, LVEF, LVdD, LVsD, and survival rate [Bielecka-Dobrowa 2013]. After 6 months of atorvastatin therapy, dilated cardiomyopathy patients have significant improvement in cardiac function, quality of life, and anti-inflammatory effects [Wojnicz 2006].

Our meta-analysis found that atorvastatin therapy shows a significantly positive influence on LVEF, 6-MWT, NTproBNP, LVsV, LDL, and CRP for dilated cardiomyopathy no obvious impact on LVEdV. In addition, statin therapy leads to a higher survival rate, without the necessity of urgent transplant in patients with cardiac insufficiency [Horwich 2004]. Atorvastatin (10 mg/day) for 1 year appears to be associated with decreased incidence of sudden cardiac death in patients with advanced chronic heart failure compared with a control group (16\% versus 36\%) [Vrtovec 2008]. Atorvastatin $40 \mathrm{mg}$ daily for 2 months followed by an individually matched dose of 10 or $20 \mathrm{mg} /$ day is associated with significantly higher probability of survival to 5 years based on a comparison of curves using the log-rank test [Bielecka-Dobrowa 2013].

Several limitations exist in this meta-analysis. First, our analysis is based on only 5 RCTs, and more RCTs with larger sample sizes should be conducted to explore this issue. Next, different doses and methods of atorvastatin were applied for dilated cardiomyopathy in the included RCTs, and they may produce different effect on the pooling results. Finally, the meta-analysis of some outcomes such as mortality can not be conducted based on current RCTs.

\section{CONCLUSION}

Atorvastatin treatment shows substantial benefits in patients with dilated cardiomyopathy and should be recommended in clinical work.

\section{ACKNOWLEDGMENT}

Funding support: YKD2018KJBW (LH)036 Joint projects of Inner Mongolia medical university science and technology million program YKD2018KJBW(LH)036.

\section{REFERENCES}

Banach M, Drozdz J, Okonski P, Rysz J. Immunological aspects of the statins' function in patients with heart failure: A report from the Annual Conference of ESC - Heart Failure 2005. Cell Mol Immunol $2005 ; 2: 433-437$.

Banach M, Mikhailidis DP, Kjeldsen SE, Rysz J. Time for new indications for statins? Med Sci Monitor 2009;15:MS1-MS5.

Bielecka-Dabrowa A, Goch JH, Mikhailidis DP, Rysz J, Maciejewski M, Banach $M$. The influence of atorvastatin on parameters of inflammation and function of the left ventricle in patients with dilated cardiomyopathy. Med Sci Monitor 2009;15:MS12-23.

Bielecka-Dabrowa A, Mikhailidis DP, Hannam S, Aronow WS, Rysz J, Banach M. Statins and dilated cardiomyopathy: Do we have enough data? Expert Opin Invest Drugs 2011;20:315-323.

Bielecka-Dabrowa A, Mikhailidis DP, Rizzo M, von Haehling S, Rysz $\mathrm{J}$, Banach $M$. The influence of atorvastatin on parameters of inflammation left ventricular function, hospitalizations and mortality in patients with dilated cardiomyopathy-5-year follow-up. Lipids Health Dis 2013;12:47.

Bleske BE, Nicklas JM, Bard RL, Brook RD, Gurbel PA, Bliden KP, et al. Neutral effect on markers of heart failure, inflammation, endothelial activation and function, and vagal tone after high-dose HMG-CoA reductase inhibition in non-diabetic patients with non-ischemic cardiomyopathy and average low-density lipoprotein level. J Am Coll Cardiol 2006;47:338-341.

Correale M, Brunetti ND, Totaro A, Montrone D, Russo AR, Fanigliulo $\mathrm{AM}$, et al. Statin therapy blunts inflammatory activation and improves prognosis and left ventricular performance assessed by tissue Doppler imaging in subjects with chronic ischemic heart failure: Results from the Daunia Heart Failure Registry. Clinics 2011;66:777-784.

Diamantis E, Kyriakos G, Quiles-Sanchez LV, Farmaki P, Troupis T. The anti-inflammatory effects of statins on coronary artery disease: An updated review of the literature. Curr Cardiol Rev 2017;13:209-216.

Gurgun C, Ildizli M, Yavuzgil O, Sin A, Apaydin A, Cinar C, et al. The effects of short term statin treatment on left ventricular function and inflammatory markers in patients with chronic heart failure. Int J Cardiol 2008;123:102-107.

Higgins JP, Thompson SG. Quantifying heterogeneity in a meta-analysis. Stat Med 2002;21:1539-1558.

Higgins J, Thomas J. Cochrane handbook for systematic reviews of interventions version 5.1.0 [updated March 2011]. The Cochrane Collaboration. 2011.

Horwich TB, MacLellan WR, Fonarow GC. Statin therapy is associated with improved survival in ischemic and non-ischemic heart failure. J Am Coll Cardiol 2004;43:642-628.

Jadad AR, Moore RA, Carroll D, Jenkinson C, Reynolds DJM, Gavaghan DJ, et al. Assessing the quality of reports of randomized clinical trials: Is blinding necessary? Control Clin Trials 1996;17:1-12.

Kaski JP, Elliott P, Group ESCW. The classification concept of the ESC Working Group on myocardial and pericardial diseases for dilated cardiomyopathy. Herz 2007;32:446-451.

Kjaergard LL, Villumsen J, Gluud C. Reported Methodologic quality and discrepancies between large and small randomized trials in metaanalyses. Ann Intern Med 2001;135:982-989.

Labos C, Brophy JM, Smith GD, Sniderman AD, Thanassoulis G. 
Evaluation of the pleiotropic effects of statins: A reanalysis of the randomized trial evidence using Egger regression. Arterioscler Thromb Vasc Biol 2018;38:262-265.

Liu M, Wang F, Wang Y, Jin R. Atorvastatin improves endothelial function and cardiac performance in patients with dilated cardiomyopathy: The role of inflammation. Cardiovasc Drugs Ther 2009;23:369-376.

Maisch B, Richter A, Sandmoller A, Portig I, Pankuweit S, Network BM-HF. Inflammatory dilated cardiomyopathy (DCMI). Herz 2005;30:535-544.

Martin J, Denver R, Bailey M, Krum H. In vitro inhibitory effects of atorvastatin on cardiac fibroblasts: Implications for ventricular remodelling. Clin Exp Pharmacol Physiol 2005;32:697-701.

McNally EM, Mestroni L. Dilated cardiomyopathy: Genetic determinants and mechanisms. Circ Res 2017;121:731-748.

Moher D, Liberati A, Tetzlaff J, Altman DG, Group P. Preferred reporting items for systematic reviews and meta-analyses: The PRISMA statement. BMJ 2009;339:b2535.

Naito R, Miyauchi K, Daida H. Racial Differences in the cholesterollowering effect of statin. J Atheroscler Thromb 2017;24:19-25.

Nunes JP. Statins and the cholesterol mortality paradox. Scot Med J 2017;62:19-23.
Oesterle A, Laufs U, Liao JK. Pleiotropic effects of statins on the cardiovascular system. Circ Res 2017;120:229-243.

Vrtovec B, Okrajsek R, Golicnik A, Ferjan M, Starc V, Schlegel TT, et al. Atorvastatin therapy may reduce the incidence of sudden cardiac death in patients with advanced chronic heart failure. J Card Fail 2008;14:140-144.

Wassmann S, Laufs U, Baumer AT, Muller K, Konkol C, Sauer H, et al. Inhibition of geranylgeranylation reduces angiotensin II-mediated free radical production in vascular smooth muscle cells: Involvement of angiotensin AT1 receptor expression and Rac1 GTPase. Mol Pharmacol 2001;59:646-654.

Weintraub RG, Semsarian C, Macdonald P. Dilated cardiomyopathy. Lancet 2017;390:400-414.

Wojnicz R, Wilczek K, Nowalany-Kozielska E, Szygula-Jurkiewicz B, Nowak J, Polonski L, et al. Usefulness of atorvastatin in patients with heart failure due to inflammatory dilated cardiomyopathy and elevated cholesterol levels. Am J Cardiol 2006;97:899-904.

Yoon SJ, Yoon YW, Lee BK, Kwon HM, Hwang KC, Kim M, et al. Potential role of HMG CoA reductase inhibitor on oxidative stress induced by advanced glycation endproducts in vascular smooth muscle cells of diabetic vasculopathy. Exp Mol Med 2009;41:802-811.

Yoshida T, Hayashi M. Pleiotropic effects of statins on acute kidney injury: Involvement of Kruppel-like factor 4. Clin Exp Nephrol 2017;21:175-181. 